\title{
The use of the computer in life history research
}

\author{
JOHN BIRTCHNELL \\ Graylingwell Hospital, Chichester, PO19 4PQ West Sussex, England
}

\begin{abstract}
Methodological difficulties in conducting large-scale life history studies and the role of the computer in resolving data gathering and data analysis problems are explored. The processing capabilities of the computer are also examined as a means of advancing the area of life history research.
\end{abstract}

Life history research attempts to assess the importance of previous life experiences in influencing current mental state. Although it was inspired by the psychoanalytic viewpoint, its execution has been rigorously statistical. It has developed out of epidemiology and the investigation of the prevalence of various types of psychiatric illness in selected population groups. Life history research had its beginnings in the isolation of specific characteristics from the routine case histories of mental hospital populations (Malzberg, 1940) and the attempts of researchers to ascertain whether the incidence of such characteristics was greater than might be expected. Unfortunately, life stories of members of the general public have not been available for comparison, and the efforts of various workers to overcome this disadvantage have become noteworthy.

The relevance of computers in traditional life history research relates to the fact that the incidence of many familial characteristics is low. For example, the incidence of the death of a mother before the age of 10 years (a frequently researched experience) is approximately $4 \%$. Thus, one needs 1,000 cases in order to obtain 40 examples. If one wishes to examine this experience's effect upon different diagnostic groups, one needs larger numbers. If one wishes to examine factors that might modify or enhance its effect, one needs still larger numbers. A need for the computer in this field of research to process and analyze large volumes of data is apparent.

\section{EARLY BEREAVEMENT}

The possible effects of the early death of a parent was one of the earliest characteristics to be examined. Barry (1936), observing what appeared to be a disproportionate number of psychotic patients who had experienced early parent death in a New Jersey hospital, resorted to a study of psychotic and nonpsychotic monarchs, maintaining that they at least would have reliable reports of parent deaths. He discovered that $40 \%$ of the psychotic monarchs had lost their fathers before age 10 years and $80 \%$ had done so by the age of 18 years. F. Brown (1961) reported that $41 \%$ of a sample of depressed patients lost either parent before age 15 years, compared with $19.6 \%$ of a sample of general medical patients and an estimated loss of $12.0 \%$ calculated from the 1921 census of England and Wales. Dennehy (1966) demonstrated excessive numbers of early parent deaths in a range of diagnostic groups using the 1921 census, the 1959 claims for widows' pensions, and life tables derived from the Chester Beattie Research Institute as her source of control data. Granville-Grossman (1966) devised the original method of comparing the incidence of bereavement in schizophrenic patients with that experienced by the patients' well siblings. His findings were negative.

I examined the case records of 500 admissions to a Scottish mental hospital, noting especially the dates of parent deaths. I conducted a postal survey of a local population to obtain controls. The response proved satisfactory, and a number of significant findings emerged from the comparisons undertaken (Birtchnell, 1969, 1970a). It became clear that a sample of 500 patients was too small to take account of those factors that may have a direct bearing upon the outcome of early bereavement or to examine the type of condition to which it may give rise. The North East of Scotland Psychiatric Case Register (Baldwin, Innes, Miller, Sharp, \& Dorricott, 1965 ) enabled me to amass a sample of 6,795 referrals from the years 1963 to 1967 . Basic family data on all these cases were derived from a standard interview that formed an integral part of the Case Register operation. Comparable control data again were derived from a postal survey of the local population, providing a sample of 3,495 subjects. A further series of bereavement studies became possible, considering type of parent substitute (Birtchnell, 1971a), the influence of the presence of older and younger siblings (Birtchnell, 1971b), the social class of the parent (Birtchnell, 1972c), and the differential effect upon various diagnostic groups (Birtchnell, 1972b).

Adding MMPI data to a subsample of $8.5 \%$ to whom this test has been administered permitted the exploration of the personality characteristics of bereaved patients (Birtchnell, 1975, 1978). In both these sets of studies, it also became feasible to study the effects on adults of recent parent death (Birtchnell, 1970b, 1979). 


\section{BIRTH ORDER}

A by-product of the Case Register research was the opportunity to examine the intervening variables as possible etiological factors. Studies of sibship size (Birtchnell, 1970c), sibling constellation (Birtchnell, 1971c), birth order (Birtchnell, 1972a), and social class (Birtchnell, 1971d) were carried out. The study of birth order reveals dramatically the confusion that arose when workers, unable to obtain general population data for comparison with clinical findings, made incorrect assumptions that led to erroneous conclusions. Until 1970 , all birth order studies, without exception, relied upon a method, proposed by Greenwood and Yule (1914), for calculating expected birth order distributions. The standard procedure was based on a table, with each row representing the size of the sibship and each column, starting from the left, representing the birth rank. For each cell of such a table, assuming an even distribution within each size of sibship, the expected number would be the row total divided by the sibship size. There are, however, obvious reasons why this method does not work in practice. During the first half of the present century, sibship sizes have become progressively smaller, so that a significant relationship exists between decade of birth and sibship size (Birtchnell, 1970c). Consequently, those who come from the larger sibships of earlier years tend to be elderly, and what is more important, they also tend to be the later born members of those sibships, the earlier born ones having already died. Also, there is the effect of population growth rate. Those born during a period of rapid growth, such as that immediately following World War II, are now more likely to be early born. Using a randomly selected general population sample, it was possible to demonstrate that the true birth rank distribution was significantly different from the expected distribution calculated by the Greenwood and Yule method. As anticipated, excessive numbers of later born subjects in the larger sibships were found. It was also demonstrated that birth rank distribution is significantly related to decade of birth. When the observed birth rank distribution in various diagnostic groups was compared with decade of birth-based expected distributions calculated from the general population control sample, no significant differences emerged (Birtchnell, 1972a). Other workers (e.g., Barry \& Barry, 1967) have erroneously concluded that being late born in a large sibship carries an excessive risk of psychiatric breakdown.

In the area of birth order, the psychoanalyst Walter Toman (1959) proposed that people tend to select marital partners from sibling positions that are complementary to their own in both seniority and sex of siblings. He also considered that those marriages that are based upon such complementarity have a greater chance of success than others. This prompted me to employ a market research organization to seek out and interview
1,000 unsuccessfully married individuals and 1,000 successfully married ones to obtain information about the sibships of the subjects and their partners (Birtchnell \& Mayhew, 1977). There was no conclusive evidence of an overrepresentation of the most favorable combinations either in the total sample or in the successfully married group; neither was there a significant underrepresentation of such combinations in the unsuccessfully married group.

\section{DISENCHANTMENT WITH THE HEAD-COUNTING APPROACH}

It is not presently possible to determine the level of precision necessary to execute bereavement studies or other life history research. There is the considerable danger in controlling for certain of the more obvious and easily measurable variables, while neglecting subtle influences. Tennant, Bebbington, and Hurry (1980), in a recent review of studies related to depressive illness, accounted for factors commonly studied in epidemiological research but made only passing reference to the more psychological influences. They conveyed the impression that, with a little modification, early bereavement can be treated much like any other pathogen.

Such methodological oversights raise the question, are people's life histories so involved that they are not amenable to a systematic research approach? At the most practical level is the problem of sample size. Returning to the field of maternal bereavement, let us suppose that we have surveyed 1,000 individuals and amassed 40 (4\%) whose mothers have died in childhood. If half stay with their fathers and half do not, one is down to 20 in each category. If half of the fathers remarry and half do not, one is down to 10 in each category. If half of the stepmothers are rejecting and half are not, one is down to five. Very soon, the numbers in the various subdivisions become too small for reliable analysis. In order to obtain adequate numbers of subjects in the most elementary of subdivisions requires large original pools of subjects to draw upon. Furthermore, such large pools of subjects all need to be subjected to standardized interviews in order to have the necessary amount of information.

Ideally, life history research should be prospective, involving, say, a large cohort followed from birth. The enormous disadvantage of this approach is that it is necessary to keep track of a substantial proportion of the cohort for up to 40 years in order to cover an adequate life span. Retrospective studies, therefore, are more feasible. The most serious problem here is whether one can rely upon the memories of the subjects. Although these individuals' recall of actual events may be reliable (e.g., what happened to themselves and their siblings following their mothers' deaths), their recollection of the quality of their relationships to key figures in their early home environment may be subject to various kinds of bias. They may recall occasional bad aspects, 
or vice versa. They may proffer unrepresentative descriptions of a relationship as a way of gaining sympathy or justifying their present behavior. They may have genuinely repressed certain unpleasant memories or have been influenced by inaccurate accounts of figures in their past by other prejudiced relatives. Yarrow, Campbell, and Burton (1970) were able to compare mothers' recall of early characteristics of their children and details of the familial environment with records kept by the children's nursery school. The analyses, as Yarrow et al. (1970, p. 68) put it, "brought little honour to retrospective reports as records of behavior."

Related to this argument is the point that a methodology and form of statistical analysis would need to be developed to accommodate these special features of human life histories. McGuire (1973, p. 448) wrote: "Socially relevant hypotheses, no less than theoretically relevant hypotheses, tend to be based on a simple linear process model, a sequential chain of cause and effect which is inadequate to simulate the true complexities of the individual's cognitive system or of the social system which we are typically trying to describe." And Riskin and Faunce (1972, p. 388), in a review of family interaction research, wrote: "The classical, scientific experimental method, with its independent and dependent variables, may not be directly transferable as a model for some frameworks of family interaction studies." What these writers are referring to is the inappropriateness of viewing social and familial interactions in terms of the simple one-to-one, "a-causes-b" type of relationship. What complicates research of this kind is the fact that a degree of circularity develops between " $a$ " and " $b$." A woman's relationship to her father may have influenced her choice of marriage partner. From this point on, she may see in her husband, characteristics that remind her of her father and affect the way she treats her husband. Furthermore, her father may still be alive, and the relationship that develops between her husband and her father affects the way each relates back to her. And this, in turn, affects the way she relates to each of them.

\section{CURRENT RESEARCH}

My present research represents a compromise position. Having abandoned the selection of isolated factors in large samples of patients and general population controls, I have attempted to study smaller samples of subjects in greater detail. My first step in this direction, again in the field of early bereavement, was to identify from the original Case Register sample of 6,795 psychiatric patients 160 women whose mothers had died before the age of 11 years. I selected, for comparison, a further 80 women, matched by decade of birth, who were brought up by both natural parents, neither of whom had died before the patient was 26 years old. I obtained the clinical case records of these 240 patients and extracted all relevant information regarding their upbringing, their marriages, and their psychiatric histories. Unfortunately, the quality of recording was extremely variable and there were a good many gaps in the information available. What should be borne in mind, however, is the fact that, since the incidence of early bereavement is so low, it is difficult to accumulate samples of adequate size. For all its disadvantages, a sample of 160 cases is much larger than any that have been previously reported and offers some opportunity for breakdown into its component parts.

Some important preliminary findings have emerged (Birtchnell, 1980). There appeared to be no obvious differences between the early bereaved the the nonbereaved women in terms of age at first breakdown, degree of involvement with the psychiatric services, personality, diagnostic distribution, or suicidality. There were, within the sample, 50 women who reported deprived treatment from their replacement mothers. The mean age at first breakdown of this subgroup was significantly earlier than that of the remainder of the sample. This group was also rated as more vulnerable and insecure, more inclined to a neurotic rather than an endogenous form of depression, and more prone to anxiety. The results suggest that the quality of relationships to parent figures may prove to be a more important area of study than the loss of them.

Having examined a large sample of early bereaved psychiatric patients and determined their clinical characteristics, I decided to seek out a sample of early bereaved women in the community to discover (1) how they compared with bereaved patients in terms of life experiences and (2) how they fared in comparison with another community sample who had not been early bereaved. In order that all community women should have experienced the same length of life, I determined that all subjects should be between 40 and 49 years of age. The women were identified by carrying out a postal survey of all women in this age group. Each was then interviewed in her home and asked to provide a full life history. A more desirable method would have been for the women to have been observed in a variety of life situations and for accounts of their behavior to have been provided by friends and relatives. Due to lack of resources, these refinements were not possible. The one distinct advantage of community samples, in contrast to clinical samples, was that all subjects were questioned according to a standard interview schedule such that a minimum amount of information was available for each subject. It was discovered that the early bereaved women did not appear to have been seriously affected by their experience. They appeared to have made good marriages and to have led reasonably normal lives. The incidence of psychiatric disturbance was surprisingly low and was, in fact, no greater than that among the control women.

\section{THE VERBAL VS. THE NUMERICAL}

The information derived from case records and the life histories reported by the interviewed subjects is represented verbally. The successful analysis of life 
histories depends largely upon the extent to which the verbal material can be converted into suitable numerical form. The temptation is great to become unduly preoccupied with those items that are already numerical or can easily be converted into numerical form. Thus, researchers tend to concern themselves with such issues as whether or not events occur, ages at which they occur, the number of times they occur, and how long they go on. Much useful work can be carried out within this limited framework, but it is probable that more interesting developments might ensue from the conversion of the less obviously translatable verbal information into analyzable form. It is likely that much clinical information or interview data remain unanalyzed simply because the researcher has balked at the task of organizing it into a form that a computer programmer can handle.

In life history research, the interface between the verbal description and the numerical representation of that description is a highly sensitive area. The translation of the verbal into the numerical represents a point of no return: Once a set of numbers has been produced, the source from which they are derived becomes irrelevant. The meaningfulness of these results depends upon how successfully the collector of data and the programmer are able to communicate with each other.

The obvious way to convert verbal data into numerical data is to devise various types of ratings that give scores according to predetermined criteria. Such ratings need to be carefully worked out, such that the maximum amount of verbal material is used, but excessive cleaning up of data may eliminate important information.

\section{THE IDIOGRAPHIC VS. THE NOMOTHETIC}

Nowhere is the conflict between the idiographic and the nomothetic approach more pertinent than in the area of life history research. The idiographic approach, which emphasizes the uniqueness of each individual life story, is essentially the province of the psychotherapist. The nomothetic approach, which is concerned with extracting rules and generalizations from studies of groups of individuals, is the province of the epidemiologist. The fundamental difference between these approaches is that the former operates vertically back and forth through the time continuum of the individual's memory and the latter operates horizontally across groups, selecting isolated items of data from each member of each group. Making meaningful connections within the human life story is a daunting task.

The single-case approach is not entirely the province of the psychotherapist. A small number of researchers, notably Shapiro (1963) and Stephenson (1953) have proposed that there are valid scientific criticismis that may be leveled at what they term "group-centered" approaches, which are circumvented by the "individualcentered" approach. With groups, the researcher is concerned always with a central tendency that says nothing about any one member of the group. The results obtained are used in such a way as to obscure the actual processes that may be at work. Shapiro (Note 1) reported that he would not anticipate very great methodological difficulties in a single-case approach to life history research. One would have a graph, the baseline of which would consist of relevant life events. Against these events would be plotted changes in target variables relevant to the research. There would be a separate graph for each individual. Single-case research may turn out to be no less complex than the more conventional epidemiological studies, in which case the data processing facilities of the computer may be required.

Returning to the theme of early bereavement, it would seem that the life story needs to be broken down into episodes, some having protective effects and others having aggravating effects. It is here that the computer can play a new and more sophisticated role in the analysis of life histories. Just as computers are currently used to formulate a diagnosis on the basis of medical history and presenting symptoms, so they could in time assess mental health prospects on the basis of key episodes in the life history. Before this can happen, it will be necessary to perfect methods of accurately describing the quality of relationships and the stressfulness of well-defined life events. Already, some progress in this direction has been made. Classification and measurement of children's reports of parental behavior have been attempted by Parker (1979) and Schaefer (1965). Methods of assessing marriage have been reported by Ferreira and Winter (1974) and Quinton, Rutter, and Rowlands (1976). A system of quantifying the adequacy of social networks has been established by Henderson (1977). Finally, a good deal of work on stressful life events has been carried out by G. Brown (1974) and Paykel (1978).

One important problem in drawing upon people's accounts of their life stories and life situations is that their descriptions may well be colored by their present emotional state. Retrospective accounts of early events are particularly difficult to deal with in this respect. In the case of provoking agents, G. Brown, Harris, and Copeland (1977) strongly adhere to the principle that judges should independently determine the likely traumatic effect of events and circumstances, irrespective of the patient's own feelings on the matter. Although this offends the psychoanalyst clinician, it avoids the criticism leveled against much life events research that the sufferer attempts to justify his emotional state by reference to the recent event. This is a complex issue that has yet to be adequately resolved.

The basis of life history research is the human life cycle: The individual leaves his family or origin, enters into familial limbo, forms his own family of procreation, and has children; his children leave home, form their family of procreation, and have children of their own. Through the course of this sequence, key relationships 
are formed with parents, siblings, marital partners, neighbors, and children. The source of data will continue to be detailed written accounts, obtained ideally over a period of time within the setting of a trusting relationship. Such accounts should be based upon a predesigned, systematic schedule. The central problem of reliably converting these accounts into a form that the computers can handle remains. Nevertheless, future developments in life history research will depend on taking full advantage of the data processing capabilities of the computer.

\section{REFERENCE NOTE}

1. Shapiro, M. B. Personal communication, 1980.

\section{REFERENCES}

Baldwin, J. A., Innes, G, Millar, W. M., Sharp, G. A., \& DonricotT, N. A psychiatric case register in north-eastern Scotland. British Journal of Preventive and Social Medicine, $1965,19,38-42$.

BARRY, H. Orphanhood as a factor in psychosis. Journal of Abnormal and Social Psychology, 1936, 30, 431-438.

BARRY, H., \& BARRY, H. J. Birth order, family size and schizophrenia. Archives of General Psychiatry, 1967, 17, 435-440.

Bintchnell, J. Parent death in relation to age and parental age at birth in psychiatric patients and general population controls. British Journal of Preventive and Social Medicine, 1969, 23, 244-250.

Birtchnell, J. Early parent death and mental illness. British Journal of Psychiatry, 1970, 116, 281-288. (a)

Biatchnell, J. Recent parent death and mental illness. British Journal of Psychiatry, 1970, 116, 289-297. (b)

Birtchnell, J. Sibship size and mental illness. British Journal of Psychiatry, 1970, 117, 303-308. (c)

Birtchnell, J. A case register study of bereavement. Proceedings of the Royal Society of Medicine, 1971, 64, 279-282. (a)

Birtchneli, J. Early parent death in relation to sibship size and composition in psychiatric patients and general population controls. Acta Psychiatrica Scandinavica, 1971, 47, 250-270. (b)

Birtchnell, J. Mental illness in sibships of two and three. British Journal of Psychiatry, 1971, 119, 481-487. (c)

Brtechnell, J. Social class, parental social class and social mobility in psychiatric patients and general population controls. Psychological Medicine, 1971, 1, 209-221. (d)

Birtchenel, J. Birth order and mental illness: A control study. Social Psychiatry, 1972, 7, 167-179. (a)

Birtchnell, J. Early parent death and psychiatric diagnosis. Social Psychiatry, 1972. 7. 202-210. (b)

Bintchnell, J. The interrelationship between social class, early parent death and mental illness. Psychological Medicine, 1972, 2, 166-175. (c)

BirtchneLl, J. The personality characteristics of early bereaved psychiatric patients. Social Psychiatry, 1975, 10, 97-103.

Birtchnell, J. Early parent death and the clinical scales of the Minnesota Multiphasic Personality Inventory (MMPI). British
Journal of Psychiatry, 1978, 132, 574-579.

BirTchnell, J. Some MMPI characteristics of psychiatric patients whose breakdown followed recent parent death. Sociol Psychiatry, 1979, 14, 181-186.

Birtchnell, J. Women whose mothers died in childhood: An outcome study. Psychological Medicine, 1980, 10, 699-713.

Birtchnelt, J., \& MaYhew, J. Toman's theory: Tested for mate selection and friendship formation. Journal of Individual Psychology, 1977, 33, 18-36.

Brown, F. Depression and childhood bereavement. Journal of Mental Science, 1961, 107, 754-777.

Brown, G. W. Meaning, measurement and stress of life events. In B. S. Dohrenwend \& D. P. Dohrenwend, Stressful life events: Their nature and effects. New York: Wiley, 1974.

Brown, G. W., Harkis, T., \& Copeland, J. Depression and loss. British Journal of Psychiatry, 1977, 130, 1-18.

Dennehy, C. M. Childhood bereavement and psychiatric illness. British Journal of Psychiatry, 1966, 112, 1049-1069.

Ferreira, A. J., \& Winter, W. D. On the nature of marital relationships: Measurable differences in spontaneous agreement. Family Process, 1974, 13, 355-369.

Granville-Grossman, K. L. Early bereavement and schizophrenia. British Journal of Psychiatry, 1966, 112, 1027-1034.

Greenwood, M., \& Yule, G. U. On the determination of size of family and of the distribution of characters in order of birth from samples taken through members of sibships. Journal of the Royal Statistical Society, 1914, 77, 179-197.

Hendenson, A. S. The social network, support and neurosis. British Journal of Psychiatry, 1977, 131, 185-191.

Malzberg, B. Social and biological aspects of mental disease. Utica, New York: State Hospitals Press, 1940.

McGuire, W. J. The yin and yang of progress in social psychology. Journal of Personality and Social Psychology, 1973, 26, 446-456.

Parker, G. A parental bonding instrument. British Journal of Medical Psychology, 1979, 52, 1-10.

PAYKel, E. S. Contribution of life events to causation of psychiatric illness. Psychological Medicine, 1978, 8, 245-253.

Quinton, D., Rutter, M., \& Rowlands, O. An evaluation of an interview assessment of marniage. Psychological Medicine, 1976, 6, 577-586.

Riskin, J. M., \& Faunce, E. E. An evaluation review of family interaction research. Family Process, 1972, 11, 365-455.

SCHAEFER, E. S. A configurational analysis of children's reports of parent behavior. Journal of Consulting Psychology, 1965, $29,552-557$.

Shapiro, M. B. A clinical approach to fundamental research with special reference to the study of the single patient. In P. Sainsbury \& N. Kreitman (Eds.), Methods of psychiatric research. London: Oxford University Press, 1963.

STEPHENBon, W. The study of behavior. Chicago: University of Chicago Press, 1953.

Tennant, C., Bebbington, P., \& Hurry, J. Parental death in childhood and risk of adult depressive disorders: $A$ review. Psychological Medicine, 1980, 10, 289-299.

Toman, W. Family constellation as a character and marriage determinant. International Journal of Psycho-Analysis, 1959, 40, 316-319.

Yarhow, M. R., Campeell, J. D., \& Burton, R. V. Recollections of childhood. A study of the retrospective method. Monographs of the society for Research in Child Development, 1970. 35(5, Serial No. 138). 